\title{
Discrimination of invaded and native species sites in a semi-desert grassland using MODIS multi-temporal data
}

\author{
C. HUANG*†§, E. L. GEIGER + W. J. D. VAN LEEUWEN $\S$ and \\ S. E. MARSH§ণ \\ $\nmid$ Department of Geomatics, National Cheng Kung University, 1 University Road, \\ Tainan 70101, Taiwan \\ †Department of Plant Biology, North Carolina State University, 2115 Gardner Hall, \\ Campus Box 7612, Raleigh, North Carolina 27695, USA \\ §Office of Arid Lands Studies, University of Arizona, Tucson, Arizona 85719, USA \\ -Department of Geography and Regional Development, University of Arizona, Tucson, \\ Arizona 85721, USA
}

(Received 6 June 2007; in final form 15 July 2008)

\begin{abstract}
Over the past several decades, one of the most significant changes in semidesert grasslands of the southwestern US has been the invasion of South African grass Eragrostis lehmanniana. The objective of this study was to characterize the phenology of systems occupied by E. lehmanniana and/or native grasses using time-series of field observations and the Moderate Resolution Imaging Spectroradiometer Normalized Difference Vegetation Index (MODIS NDVI) and brightness (red and near-infrared reflectance) data. Results demonstrated that it was possible to use NDVI and/or spectral reflectance data to discern the phenological differences across a gradient of E. lehmanniana infested grasslands due to variations in plant biodiversity, morphology and seasonal productivity. This work establishes the feasibility of integrating field and MODIS vegetation and spectral time-series data to characterise landscapes dominated by different herbaceous species, which in turn provides opportunities to monitor E. lehmanniana in semi-arid environments at a large spatial scale.
\end{abstract}

\section{Introduction}

One of the most significant changes in vegetation in the drylands of the southwestern US during the past century has been the invasion of non-indigenous species (McPherson and Weltzin 2000). Eragrostis lehmanniana (Lehmann lovegrass), a tufted perennial bunchgrass from South Africa, is one of the most troublesome species in this arid region. Eragrostis lehmanniana was introduced into Arizona in 1932 to control soil erosion and provide forage for cattle. This nonnative species is well adapted to the climatic patterns and edaphic conditions of the region (Cable 1971, Cox et al. 1988). By 1984, this species had expanded onto $1450 \mathrm{~km}^{2}$ of drylands, representing only half of the area that had been directly sown (Cox and Ruyle 1986). Based upon environmental conditions at sites currently

\footnotetext{
*Corresponding author. Email: choying@mail.ncku.edu.tw
} 
occupied by E. lehmanniana, it could potentially inhabit over $70000 \mathrm{~km}^{2}$ (Schussman et al. 2006). Eragrostis lehmanniana is a prevailing species (Ortega and Pearson 2005) and one of its most significant impacts on the environment is the reduction of native plant diversity resulting in significant ecosystem vulnerability (Bock et al. 1986, Williams and Baruch 2000). In addition, the ecophysiological traits of E. lehmanniana, including its prolific growth rate, highly lignified and persistent biomass result in areas of higher biomass compared to areas dominated by native grasses (Geiger 2006). This ultimately could cause changes in fire regime (Cable 1971, D’Antonio and Vitousek 1992). These growth characteristics, coupled with enhanced seed germination after fire, would permit rapid proliferation and dominance in new environments after disturbance.

It is a challenge to monitor non-native species over large spatial extents. One of the most common methods is through the use of remote sensing to map the spatial distribution of non-native species. Remote sensing has the potential advantage of quickly monitoring the spread of non-native species over larger spatial extents, in contrast to conventional field-based methods. Generally, a direct approach has been used, based upon detecting the textures (spatial aggregation and patchiness) of nonnative invaded environments or by capturing the physiological and phenological uniqueness of these species in spectral space. The most straightforward approach is to use high spatial resolution images (e.g. pixel size $\sim 1 \mathrm{~m}$ ) with visual inspection, image classification and/or texture analysis techniques to delineate the spatial distribution of non-native species. The rationale of this approach is to pinpoint these species based on their unique spatial patterns (Fuller 2005) or phenological characteristics (Everitt et al. 1995, 1996, 2001). Recently, efforts focused on discriminating the spectral signatures of non-native species by using hyperspectral remote sensing, together with advanced statistical techniques (Anderson et al. 2005, Asner and Vitousek 2005, Glenn et al. 2005, Lawrence et al. 2006, Miao et al. 2006). The main advantage of using hyperspectral data is its ability to select specific spectral regions that are sensitive to the abundance of non-native species for analysis (Underwood et al. 2003).

There are several drawbacks to these high spatial resolution and hyperspectral remote sensing approaches. The major disadvantages of using high spatial resolution data are: (1) the presence of many non-native species is not discernable (e.g. herbaceous plants), even with some of the finest spatial resolution data (e.g. $7 \mathrm{~cm}$ aerial videography; Drake 2000) and (2) phenological changes due to the presence of non-native species might not be recognisable due to coarse spectral resolution. In addition, visual inspection and photo-interpretation are labour and time intensive, and the quality of the results is highly dependent on the skills and experience of the interpreter (Anderson et al. 1993a). Therefore, a high spatial resolution remote sensing approach is less feasible for large-area studies, and the quality of the mapping is uncertain. The algorithms used to label pixels occupied by non-native species in hyperspectral images are complicated and, in many cases, positive empirical results do not necessarily connect to physiological aspects of the plant or its ecological setting permitting extension of the techniques to large areas. Moreover, the robustness of using hyperspectral data to distinguish species types is still uncertain due to the high similarity of spectral signatures among them (Asner 1998, Okin et al. 2001). There are two additional constraints that limit the ability of both high spatial and hyperspectral data for large-scale non-native species studies: small footprints (spatial extents) and high data cost. 
Understanding the temporal and spatial variations of remote sensing data to areas infested with non-native species and tying their presence and response to ecological processes are crucial for effective monitoring of non-native species. Previous studies have shown that it may be possible to monitor vegetation dynamics by using inexpensive, large-footprint and high temporal resolution satellite data (Justice et al. 1985, Prince and Tucker 1986). Several phenological metrics, such as vegetation onset time, end time, duration of growth and rate of vegetation green-up and senescence can be derived from remote sensing time-series data (Reed et al. 1994). Bradley and Mustard (2005) showed that response of a non-native cheatgrass (Bromus tectorum) was amplified by rainfall, and it may be possible to locate cheatgrass-infested areas, based on its unique phenological response or signature. Hence, the objective of this study was to characterize the temporal and spatial variations of high temporal resolution remote sensing vegetation and brightness (red and near-infrared (NIR) reflectance) signals to native grass communities and those invaded by E. lehmanniana. Figure 1 shows typical views of areas dominated by native grasses and E. lehmanniana in semidesert grasslands. It is evident that the area dominated by native grasses is visually more heterogeneous than areas infested by E. lehmanniana. Native grass sites contain diverse annual/perennial grasses and herbaceous dicots with distinct growing seasons. Therefore, sites dominated by native grasses likely contain green vegetation throughout the year. In contrast, E. lehmanniana generates a thick, dense and homogeneous layer of green biomass in the summer growing season or bright, yellowish litter cover during non-growing time periods. Therefore, we predict that:

(1) The signal of vegetation in remote sensing data would be greater from sites infested by E. lehmanniana compared to native grass sites during the summer growing season due to non-native species having higher productivity.

(2) During non-growing time periods, vegetation signals would be stronger in native grass dominant sites than E. lehmanniana invaded sites, representing the contribution from annual grasses and herbaceous dicots.

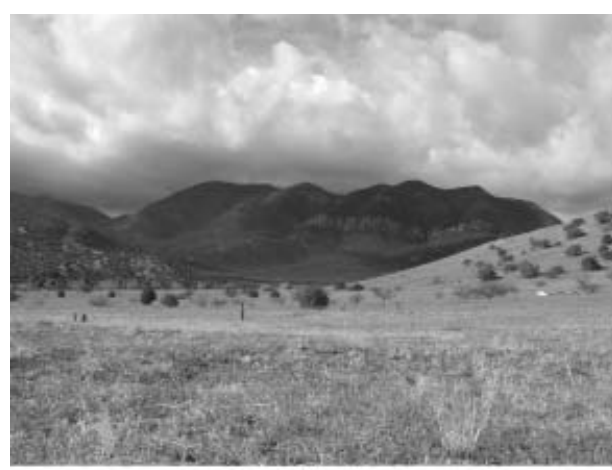

(a)

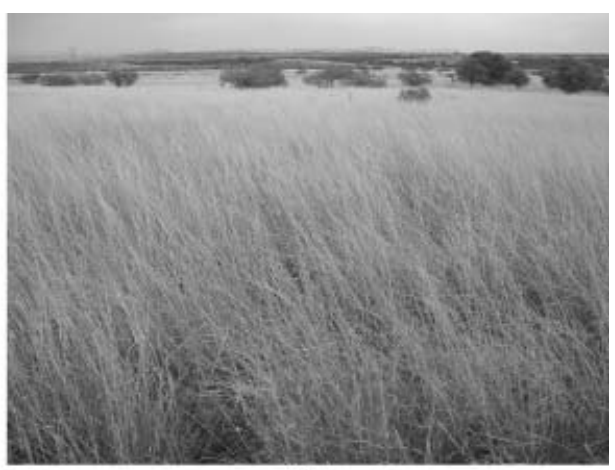

(b)

Figure 1. Typical views of landscapes dominated by (a) native grass and (b) E. lehmanniana. Both pictures were taken before the initiation of summer monsoonal rainfall (native grass: 2 April 2003, Eragrostis lehmanniana: 4 May 2004) at Fort Huachuca Military Reservation, Arizona, USA. 
(3) Vegetation signals and brightness from sites dominated by native grasses are more temporally stable but spatially variable than sites invaded by $E$. lehmanniana. Plant biodiversity could be the determinant dictating these variations.

\section{Methods}

\subsection{Study area}

This study was conducted at Fort Huachuca Military Reservation (FHMR) $\left(31^{\circ}\right.$ $34^{\prime} \mathrm{N}, 110^{\circ} 26^{\prime} \mathrm{W}$ ) located in southern Arizona, USA (see figure 2). The spatial extent of the reservation is about $330 \mathrm{~km}^{2}$. The primary vegetation can be generally defined as semi-desert grassland, which is a system with a background of grass and sporadically distributed trees and shrubs (Belsky 1990, McPherson 1997, Scholes and Archer 1997). The mean annual precipitation is $366 \mathrm{~mm}$ and the variation is pronounced (standard error $\mathrm{SE}=38 \mathrm{~mm}$ ) based on eight years (1998-2005) of observation from five meteorological stations (figure 2). About two-thirds of the

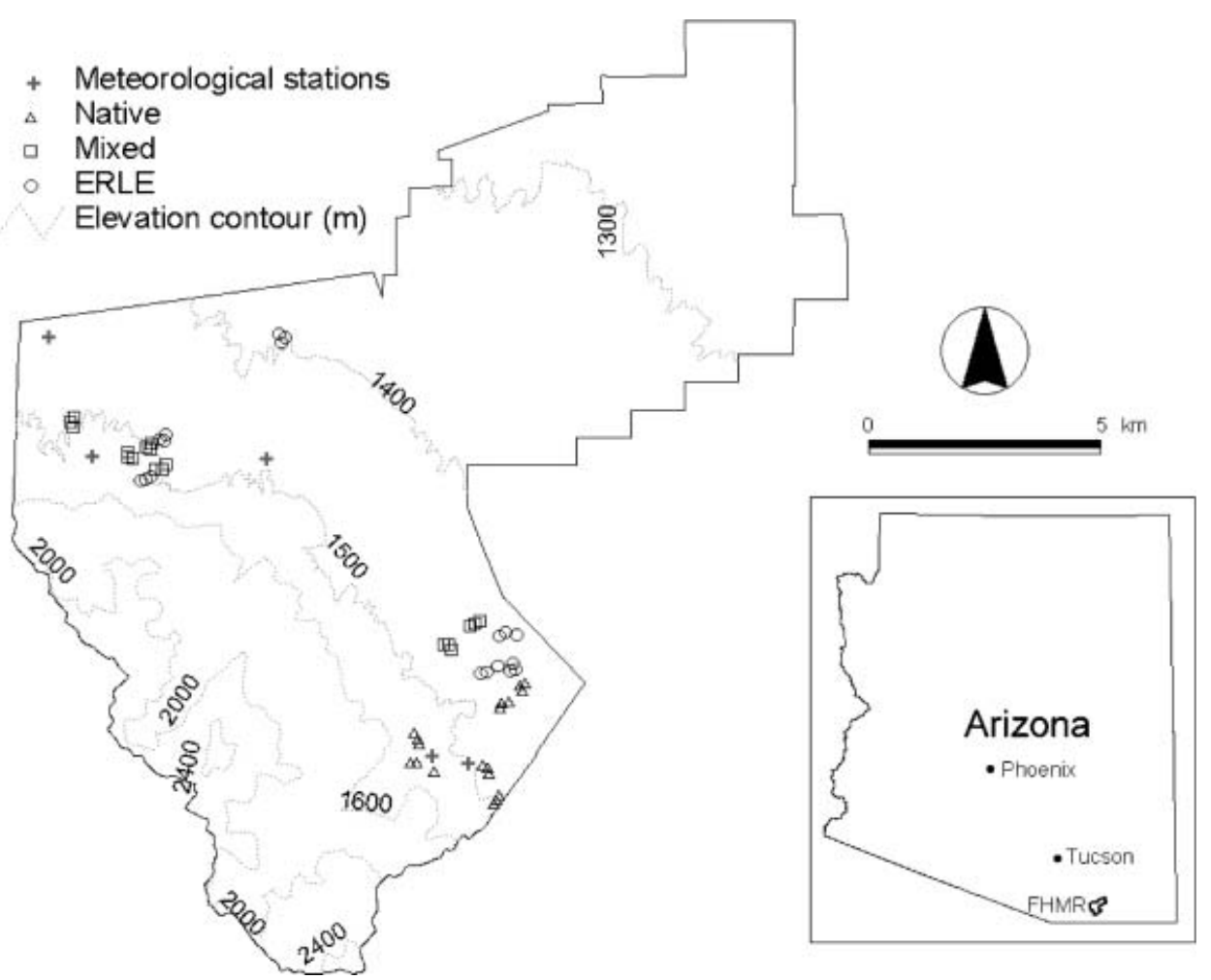

Figure 2. The site map of Fort Huachuca Military Reservation (FHMR), Arizona, USA. Field sampling plots, established between $1350 \mathrm{~m}$ and $1600 \mathrm{~m}$ elevation, are indicated by open triangles (native: native vegetation), squares (mixed: mixture of native and non-native grasses) and circles (ERLE: sites dominated by Eragrostis lehmanniana). Meteorological station locations are shown as grey plus signs. The location of FHMR and major cities of Arizona are shown in the lower right corner. 
precipitation falls between July and September known as the 'summer monsoons', and one-third falls between October and April. This area rarely receives rainfall in May and June prior to the initiation of summer monsoons. FHMR is an active installation of the US Army and therefore livestock grazing has been excluded for more than five decades (Biggs et al. 2002). The most pronounced disturbances in the study area are fire (controlled burns and wild fires) and military training.

\subsection{Field site selection and characterization}

Eighteen sites at FHMR were selected for this study (figure 2). These sites were dominated by herbaceous plants, and woody cover was less than $15 \%$ based on ocular estimation. Each site was a composite of three $0.01 \mathrm{~km}^{2}$ square sub-plots that were selected by locating six sites within each of three types of grassland communities (native, mixed and ERLE (abbreviation for E. lehmanniana)), representing a gradient of E. lehmanniana invasion. Sites were classified based on a priori visual surveys, and these designations were consistent throughout the duration of the study. Wild fires were not common in drylands of southern Arizona post-Anglo settlement (McPherson 1995). At FHMR, adequate fine fuels in conjunction with regular ignition sources from military training activities allowed for a fire regime similar to historical regimes (every 5-10 years). Areas that had experienced wild fires during the past 9 years were excluded from site selection. Field biomass sampling was conducted twice each year during the late spring (April) and autumn (September), starting from autumn 1999. During these two time periods, herbaceous plants achieved peak standing biomass after the intensive summer monsoons and intermittent spring rains. All herbaceous plants rooted in 25 quadrats of dimension $1.0 \times 0.5 \mathrm{~m}$, randomly located in sub-plots, were clipped and all species were recorded. Quadrats were relocated if they coincided with previously clipped quadrats or were inaccessible because they were beneath dense canopies of shrubs. To obtain standing biomass, plants were harvested at $2.5 \mathrm{~cm}$ above the ground for perennial grasses and at ground level for all other annual grasses and herbaceous dicots. Surface litter (defined as dead plant tissue detached and lying on the ground) was excluded from analysis. Samples were oven-dried at $65^{\circ} \mathrm{C}$ for more than 48 hours and weighed to the nearest $0.1 \mathrm{~g}$. Herbaceous plant diversity of these sites was assessed using species richness and Simpson's diversity index as indicators. Species richness is the number of species, and Simpson's diversity index is a biodiversity measurement that takes into account both species richness and evenness (Begon et al. 1996).

\subsection{The Moderate Resolution Imaging Spectroradiometer (MODIS) data acquisition}

The remotely sensed data used in this study was the Normalized Difference Vegetation Index (NDVI) time-series data derived from a MODIS. The MODIS is a high temporal resolution and multi-spectral spaceborne sensor. It is on board the Terra platform, with a daily revisit time at 10:30 a.m. at this latitude. It has been acquiring data since early spring of 2000, and simultaneously acquires data in 36 spectral bands at approximately 250, 500 and $1000 \mathrm{~m}$ spatial resolution (Justice et al. 1998). The MODIS pixel geolocation accuracy is very good at approximately $50 \mathrm{~m}$ at nadir (Wolfe et al. 2002). The MODIS NDVI is one of the most commonly used products to study terrestrial environments at regional and global scales. The red and NIR band data characterize surface reflectance values $(0-100 \%)$ and can be 
considered the brightness of an object relative to incoming solar radiation. The spectral regions of the MODIS red and NIR bands are $620-670 \mathrm{~nm}$ and $841-876 \mathrm{~nm}$, respectively. The NDVI is an index to enhance the vegetation signals by ratioing the difference between NIR and red reflectance values and the summation of these two (Rouse et al. 1974).

The MODIS NDVI data (and corresponding red and NIR reflectance) were used to derive vegetation signal and spectral properties in native, mixed and ERLE sites from the bi-weekly (16 days) composites (MOD13Q1) acquired from the Land Processes Distributed Active Archive Centre, located at the US Geological Survey (USGS) Centre for Earth Resources Observation and Science (http:// LPDAAC.usgs.gov). There are a total of 23 time period composites per year. To generate composite MODIS NDVI data, the highest NDVI value within each 16 day time period with the optimal view angle for each pixel was selected for the final product in order to provide a consistent data product and minimize data errors (Huete et al. 2002). The quality of all data was analysed using the MODIS snow and cloud mask data and were free of contamination.

\subsection{Variations of MODIS NDVI-biomass relationships and time-series data}

The size of each $0.01 \mathrm{~km}^{2}$ sub-plot was smaller than the MODIS NDVI, red and NIR pixels (approx. $250 \times 250 \mathrm{~m}$ ), and sub-plots usually did not lie exclusively within a single pixel. Therefore, to derive the most representative signal, an area weighting method was employed that assigned different weights for each overlaid pixel based on the area covered, and this was applied to precisely compute the timeseries values for these sub-plots. Regression models were developed to estimate total herbaceous biomass using seasonal field observations as the independent variable and corresponding mean NDVI as the dependent variable (MODIS period 6-8 (22 March-8 May) for spring and period 16-18 (29 August-15 October) for autumn). Additionally, the NDVI, red and NIR reflectance for each type of site (native, mixed or ERLE) were averaged and plotted against MODIS periods and climate data to study the impacts of seasonality and climate dynamics on variation in the time-series data. Daily mean air temperature and precipitation from five weather stations close to the sampling sites (figure 2) were acquired from the FHMR meteorological laboratory. These data were averaged to 16 day time periods to match the MODIS acquisition period. Three main analyses were implemented to investigate the variations of satellite time-series data among different sites.

2.4.1 Direct comparison and difference testing of time-series data. Mean NDVI, red and NIR data from native, mixed and ERLE sites in each MODIS period were compared to see which plant communities produced the highest and/or lowest values. Differences in the NDVI, red and NIR data among these plant communities were tested for each MODIS time period to determine which seasons might provide distinct separation from the time-series data. In order to investigate the separablility of the MODIS NDVI, red and NIR time-series data between native, mixed and ERLE sites, we applied the Tukey-Kramer multiple comparison procedure to test the NDVI and spectral difference between these three vegetation communities. The Tukey-Kramer multiple comparison procedure uses the unique structure of the multiple comparisons by selecting a specific multiplier from the studentized range distributions rather than from the $t$ distributions (Ramsey and Schafer 1997). This is a statistical method to test 
difference among several groups, and the overall (or family-wise) confidence interval is not as strict as the $F$-test and not as conservative as other comparison methods (e.g. Scheffé's procedure; Ramsey and Schafer 1997).

2.4.2 Temporal variation of time-series data. Temporal variations (temporal coefficient of variation (CV)) of mean NDVI, red and NIR time-series data for each plant community was computed by ratioing the standard deviation (SD) to the mean with time (a single year and over the entire observation time span), and converting it to a percentage by multiplying by 100 .

2.4.3 Temporal-spatial variation. Variability, as measured by the CV of NDVI, red and NIR data within native, mixed or ERLE sites (measuring within group variability across the landscape) with time (a single year and over the entire observation time span), was assessed. This CV was derived by ratioing the SD to the mean at one time period, and converting it to a percentage by multiplying by 100. The statistical difference of the CV with time between the three plant communities was tested using an autoregressive model of order 1 (AR(1)), which is a time-series correction model that adjusts the SE to account for the serial correlation that violates the assumption of independence (Ramsey and Schafer 1997).

\section{Results}

Data presented in this study involved three plant communities (native, mixed and ERLE) through different seasons. To clarify presentation of the data over time for each plant community, we partitioned the 23 MODIS NDVI 16 day data cycles per year into four periods. They were MODIS periods 1-5, 6-11, 12-17 and 18-23, which corresponded to the time periods 1 January to 21 March, 22 March to 25 June, 26 June to 29 September and from 30 September to the end of the calendar year, respectively. These four periods roughly represent dormant, growing, flowering and senescent vegetation in southern Arizona. In addition, we adopted a consistent set of colours and symbols to illustrate the results (see table 1).

\subsection{Vegetation of semi-desert grasslands}

A summary of ecological characteristics for each plant community, total herbaceous and E. lehmanniana biomass for spring and autumn from 1999 to 2004 is depicted in table 2. Data showed that semi-desert grasslands in southern Arizona produced more herbaceous biomass during the summer monsoon season than spring. Additionally, there was a positive trend between the total herbaceous biomass and the abundance of E. lehmanniana. A negative relationship was found between

Table 1. The colour scheme for seasonality of the Moderate Resolution Imaging Spectroradiometer (MODIS) time periods used in figure 5 and symbols for the plant communities utilized in figures $2-5$.

\begin{tabular}{lllll}
\hline $\begin{array}{l}\text { Colour } \\
\text { scheme }\end{array}$ & \multicolumn{1}{c}{ MODIS (date) } & Phenology & \multicolumn{1}{c}{ Symbol } & \multicolumn{1}{c}{ Site type } \\
\hline & 1-5 (01 January-21 March) & Dormant & Triangles $(\triangle)$ & Native \\
& 6-11 (22 March-25 June) & Growing & Squares ( $\square)$ & Mixed \\
& 12-17 (26 June-29 September) & Flowering & Circles ( $\bigcirc)$ & ERLE \\
& 18-23 (30 September-31 December) & Senescent & & \\
\hline
\end{tabular}


Table 2. Summary of ecological characteristics and seasonal biomass of all herbaceous plants and Eragrostis lehmanniana for the native, mixed and E. lehmanniana (ERLE) sites. The biomass $\left(\mathrm{g} \mathrm{m}^{-2}\right)$ values (with the standard error, SE, in parentheses) shown here are based upon data collected during 10 seasonal sampling periods from autumn 1999 to spring 2004.

\begin{tabular}{|c|c|c|c|c|c|}
\hline \multirow[b]{2}{*}{ Site } & \multirow[b]{2}{*}{ Dominant species } & \multicolumn{2}{|c|}{$\begin{array}{l}\text { Herbaceous biomass } \\
\text { (SE) }\end{array}$} & \multicolumn{2}{|c|}{$\begin{array}{l}\text { E. lehmanniana } \\
\text { biomass (SE) }\end{array}$} \\
\hline & & Spring & Autumn & Spring & Autumn \\
\hline Native & $\begin{array}{l}\text { Bouteloua eriopoda } \\
\text { B. curtipendula } \\
\text { Schizachyrium cirratum }\end{array}$ & $143.9(8.9)$ & $192.6(12.3)$ & $11.5(2.0)$ & $12.9(2.6)$ \\
\hline Mixed & $\begin{array}{l}\text { E. lehmanniana } \\
\text { E. intermedia }\end{array}$ & $165.5(8.7)$ & $204.8(12.6)$ & $93.7(7.4)$ & $104.2(6.8)$ \\
\hline ERLE & $\begin{array}{l}\text { E. lehmanniana } \\
\text { Schizachyrium sanguineum }\end{array}$ & $226.9(14.1)$ & $274.7(17.5)$ & $177.0(12.5)$ & $209.4(14.5)$ \\
\hline
\end{tabular}

the extent of E. lehmanniana invasion and herbaceous plant biodiversity (see figure 3). Native sites produced higher species richness and Simpson's diversity index values than mixed and ERLE sites throughout the observation period.

\subsection{MODIS NDVI-biomass relationships among different plant communities}

A linear relationship was found between the NDVI and total herbaceous biomass collected from native, mixed and ERLE sites through the MODIS observation period (from spring 2000 to spring 2004) (see figure 4). The NDVI was a significant $(p \leqslant 0.002$ for the coefficients of the NDVI among the models), but rather weak indicator to predict herbaceous biomass in semi-desert grasslands. Nevertheless, the predictability $\left(R^{2}=0.35\right)$ with the NDVI in native sites was superior to it in E. lehmanniana-infested sites $\left(R^{2}=0.18\right.$ for mixed sites and $R^{2}=0.23$ for ERLE).

\subsection{Phenology of semi-desert grasslands}

Vegetation dynamics were highly related to seasonal precipitation, temperature and solar radiation (see figure $5(a)$ and $5(g)$ ) in these dryland environments. Time-series NDVI data showed that there was either uni-modal or bi-modal growing seasons discernable, depending on the amount of spring rainfall. In years 2001 and 2005, FHMR received a large amount of precipitation during the summer growing season ( $220 \mathrm{~mm}$ in 2001 and $217 \mathrm{~mm}$ in 2005 from mid-July to mid-September), and the response of the NDVI to these wetter years can be seen in this time-series data. In October and early November of 2000, FHMR also received significant amounts of rainfall $(239 \mathrm{~mm})$, but the NDVI values did not increase consequently because the moisture came after the summer growing season. Based on visual inspection, distinct segregation of NDVI time-series data among the native, mixed and ERLE sites occurred during spring (mid-March to April) and/or early summer (May to July) depending on the amount and timing of rainfall.

\subsection{Direct comparison and difference testing of time-series data}

Over the entire study period, native sites produced the highest NDVI value for $82 \%$ of the MODIS periods. However, the NDVI values among these three plant communities 


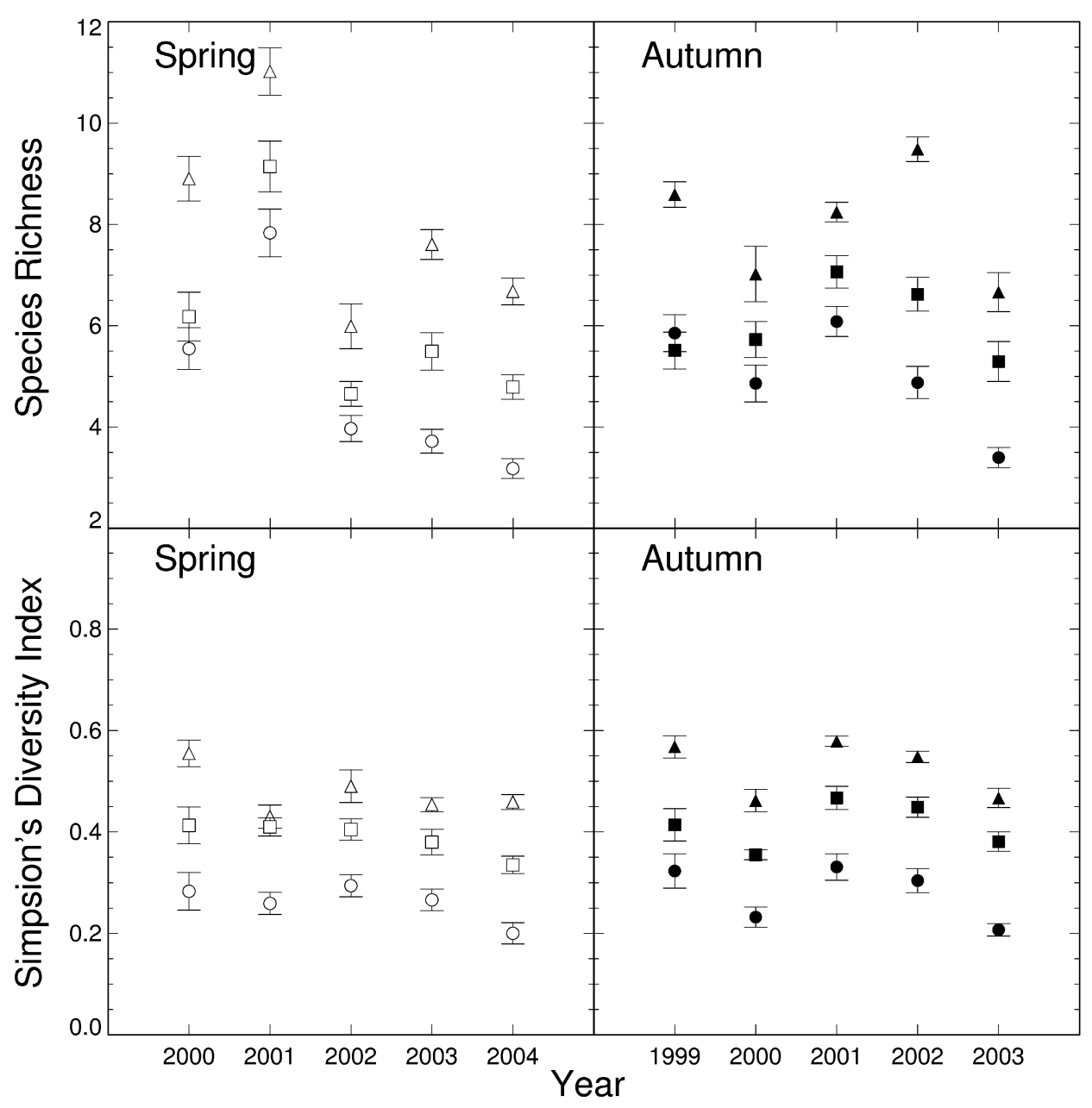

Figure 3. Species richness (top panel) and Simpson's diversity index (bottom panel) with one standard error for native, mixed and Eragrostis lehmanniana (ERLE) sites based upon seasonal field observations. Empty and filled symbols indicate that data were collected in spring and autumn, respectively. See table 1 for the meaning of each symbol.

were quite similar during the summer monsoon period and no consistent separation was found. In addition, the NDVI trajectories of mixed and ERLE sites were intertwined and no distinct separation was found with time. Temporal dynamics of MODIS red reflectance time-series data are shown in figure 5(c). They were higher in the early summer before the initiation of summer rainfalls (from May to early July) and lower during summer monsoons (August and September). The separation of these three plant community groups was not visually distinct. By direct quantitative comparison, mixed sites produced greater values (with highest reflectance in $51 \%$ of the MODIS periods) than native $(27 \%)$ and ERLE $(22 \%)$ sites. Figure $5(e)$ illustrates the temporal dynamics of the NIR data. MODIS NIR time-series data were similar to the NDVI, but appeared much more variable (note the number of spikes and dips). Conspicuous bi-modal growing seasons were evident in the NDVI time-series data for 2001 and 2004, however, they were not as distinct in the NIR time-series data. The NIR 


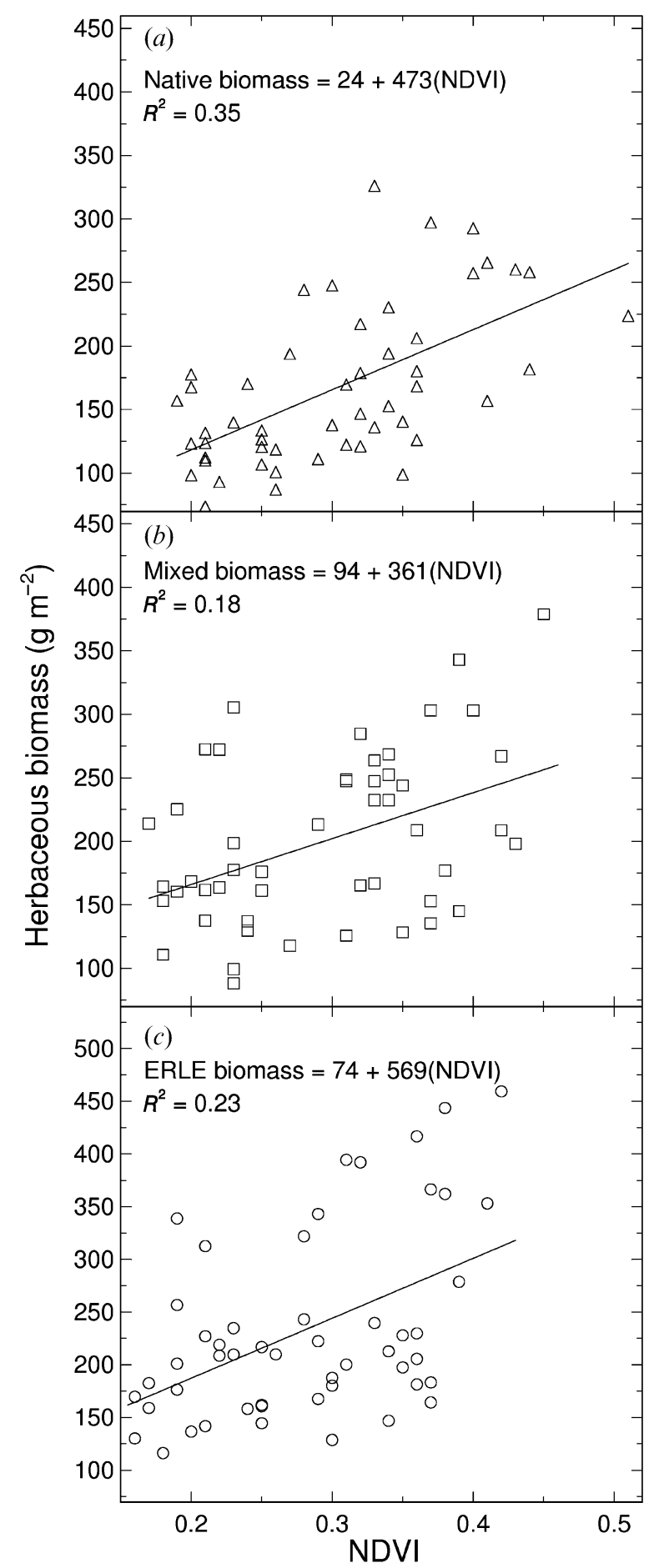

Figure 4. Predictability of the Moderate Resolution Imaging Spectroradiometer Normalized Difference Vegetation Index (MODIS NDVI) to herbaceous biomass collected in semi-desert grasslands dominated by $(a)$ native grasses $(c)$ Eragrostis lehmanniana (ERLE) or $(b)$ both during the satellite observation periods. 


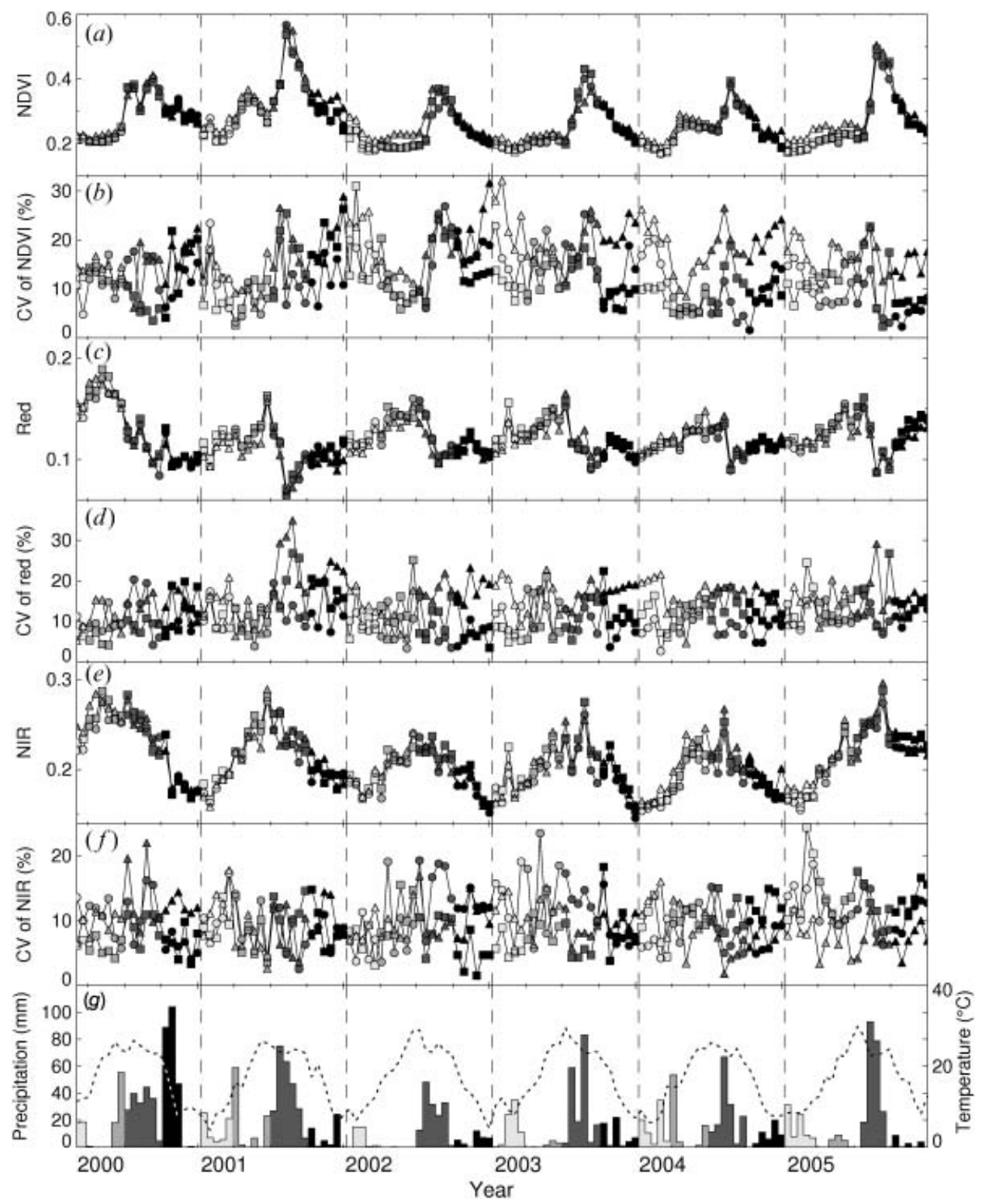

Figure 5. (a) Normalized Difference Vegetation Index (NDVI), $(c)$ red and $(e)$ near-infrared (NIR) time-series data for native, mixed and Eragrostis lehmanniana (ERLE) sites from 2000 to 2005 , respectively. Spatial variations of: $(b)$ NDVI, $(d)$ red and $(f)$ NIR with time among sites demonstrated using the coefficient of variation $(\mathrm{CV})$. $(\mathrm{g})$ Bi-weekly precipitation (bars) and temperature (dotted line) data based upon daily weather records from five stations at Fort Huachuca Military Reservation (figure 2). See table 1 for the description of symbols and colour scheme.

reflectance was higher during the summer monsoon season, and trends of the NIR time-series data can roughly distinguish the wet and dry years based on the amplitude of the signal. The temporal separation of these three plant communities was not visually distinct. Native sites produced higher NIR values (with largest reflectance 
values in $51 \%$ of MODIS periods) than mixed (40\%) and ERLE (9\%) sites, based on a direct comparison.

Table 3 lists the MODIS periods and corresponding dates that have a significant difference of $0.05(\alpha)$ between sites within the observation years based on the Tukey-Kramer multiple comparison procedure. MODIS periods with significantly different NDVI between vegetation types occurred in spring (MODIS period 5-8; 6 March-8 May) and/or early summer (MODIS period 9, 10, 12 and 13; 9 May-27 July); native sites exhibited greater greenness than mixed and/or ERLE sites during these time periods. For MODIS red reflectance, there was almost no clear separation among these three types of sites, regardless of year or rainfall. Across time, there were distinct differences in the MODIS NIR spectral response between the sites, but when they occurred was less predictable. They can be found in every season, regardless of whether it was a dry or wet year. In general, NIR reflectance within these time periods was higher in native sites than mixed or ERLE sites. In some cases (2001 and 2003), NIR reflectance of mixed sites was higher than that of ERLE in early autumn (MODIS period 16 and 17; 29 August-29 September).

\subsection{Temporal variation of time-series data}

Temporal CV of NDVI, red and NIR data to the mean values between native, mixed and ERLE sites with time are summarized in table 4. Data showed that the betweenyear temporal variation for each plant community type was much greater than the within-year variation among plant communities for the NDVI and red reflectance. The NIR reflectance was less variable among sites and through the years. Temporal variation of the NDVI of native sites was consistently lower than mixed and ERLE sites through the years, but no other clear trend was found for other spectral-index and site combinations. Due to the requirement of a large sample size for standard time-series analysis (e.g. $N>100$; Ramsey and Schafer 1997), no statistical model was applied to test the difference of these plant communities.

\subsection{Temporal-spatial variation of time-series data}

Temporal-spatial variations of NDVI, red and NIR time-series data (figure $5(b)$, $5(d)$ and 5(f), respectively) for native, mixed and ERLE sites are described in table 5. For the NDVI, an explicit pattern was found: the temporal-spatial variation of native sites was higher than mixed/ERLE sites with time, but there was no difference between mixed and ERLE sites based upon AR(1). A similar pattern was also found for these three groups in the red reflectance values, and difference between mixed and ERLE sites can be further distinguished. The patterns of temporal-spatial variation between plant community groups were less distinct in the NIR data for each year, and the only significant difference was that the ERLE sites were greater than the native sites for the entire observation period.

\section{Discussion and conclusions}

\subsection{Influences of plant morphology on remote sensing vegetation phenology and estimation of biomass}

A large body of literature has shown that the NDVI is a salient variable for estimating plant biomass, productivity and abundance in drylands (Tucker et al. 1985, Prince and Tucker 1986, Dregne and Tucker 1988, Wylie et al. 1991, Anderson 
Table 3. The difference test of the Normalized Difference Vegetation Index (NDVI), red and near-infrared (NIR) data to native, mixed and Eragrostis lehmanniana (ERLE) sites using the Tukey-Kramer multiple comparison procedure with 0.05 level of significance $(\alpha)$. Note that only the Moderate Resolution Imaging Spectroradiometer (MODIS) time periods and actual dates with a statistically significant difference are listed.

\begin{tabular}{|c|c|c|c|c|c|c|}
\hline \multirow[b]{2}{*}{ Year } & \multicolumn{2}{|c|}{ NDVI } & \multicolumn{2}{|c|}{ Red reflectance } & \multicolumn{2}{|c|}{ NIR reflectance } \\
\hline & MODIS (date) & Difference & MODIS (date) & Difference & MODIS (date) & Difference \\
\hline 2000 & None & \multirow{3}{*}{ Native $>$ ERLE } & None & \multirow{8}{*}{ Mixed $>$ native } & None & \\
\hline \multirow[t]{2}{*}{2001} & $5-7$ & & 9 (9-24 May) & & 13 (12-27 July) & Native $>$ ERLE \\
\hline & (6 March-22 April) & & & & 16 (29 August-13 September) & Mixed $>$ ERLE \\
\hline 2002 & $\begin{array}{l}\text { 8-10 } \\
\text { (23 April-9 June) } \\
\text { 12-13 } \\
\text { (26 June-27 July) }\end{array}$ & Native $>$ Mixed/ERLE & None & & 6 (22 March-6 April) & Native $>$ ERLE \\
\hline 2003 & None & & None & & 17 (14-29 September) & Mixed $>$ ERLE \\
\hline 2004 & $7-8$ & Native $>$ ERLE & None & & 11 (10-25 June) & Native $>$ ERLE \\
\hline & (7 April-8 May) & & & & $\begin{array}{l}14 \text { (28 July-12 August) } \\
23 \text { (19-31 December) }\end{array}$ & Native $>$ mixed/ERLE \\
\hline 2005 & 5-7 (6 March-22 April2) & Native $>$ mixed/ERLE & None & & None & \\
\hline
\end{tabular}


Table 4. The annual and overall temporal variations of the Normalized Difference Vegetation Index (NDVI), red and near-infrared (NIR) data for native, mixed and Eragrostis lehmanniana (ERLE) sites from 2000 to 2005 demonstrated by using the coefficient of variation (all values are percentages).

\begin{tabular}{lcccccccc}
\hline Index & Site & 2000 & 2001 & 2002 & 2003 & 2004 & 2005 & Overall \\
\hline NDVI & Native & 21.5 & 24.6 & 18.6 & 19.1 & 18.6 & 29.2 & 25.1 \\
& Mixed & 23.2 & 26.5 & 26.2 & 29.8 & 22.2 & 35.1 & 29.2 \\
\multirow{3}{*}{ Red } & ERLE & 23.3 & 27.6 & 19.5 & 26.8 & 20.6 & 32.1 & 28.1 \\
& Native & 23.2 & 17.7 & 13.0 & 12.9 & 10.9 & 12.1 & 16.5 \\
& Mixed & 23.8 & 16.9 & 13.0 & 14.3 & 9.5 & 14.7 & 16.5 \\
\multirow{2}{*}{ NIR } & ERLE & 23.5 & 18.2 & 15.0 & 13.6 & 9.4 & 13.6 & 16.5 \\
& Native & 15.8 & 13.8 & 11.0 & 13.3 & 13.7 & 14.1 & 14.7 \\
& Mixed & 16.4 & 14.7 & 10.7 & 13.5 & 13.1 & 15.4 & 15.2 \\
& ERLE & 15.1 & 13.9 & 12.2 & 13.2 & 12.0 & 15.0 & 15.1 \\
\hline
\end{tabular}

et al. 1993b, Hurcom and Harrison 1998, Al-Bakri and Taylor 2003, etc.). However, our data showed that in the case of E. lehmanniana the assumed relationship between the NDVI and biomass may not be applicable. According to field observations, sites occupied by substantial amounts of E. lehmanniana (mixed/ ERLE) contained more herbaceous biomass than native sites in the spring and postmonsoon seasons (table 2). Nevertheless, native sites produced higher NDVI values than mixed and ERLE sites, regardless of yearly rainfall amount or timing. One of the factors resulting in the disagreement between field and satellite observations can be attributed to the phenology and morphology of E. lehmanniana. The top layer of E. lehmanniana is dense, bright pale-coloured and has panicle-like inflorescence. In the secondary layer, recently senescent light-coloured dead tissue (standing litter) remains attached to live plants. Both components could obscure green signals from tiller (leaf blade) that was located at the lower stratum of the grass structure. Although E. lehmanniana-infested sites (ERLE/mixed) would produce greater amounts of biomass than native grass dominant areas during the summer monsoon

Table 5. The temporal-spatial variations of Normalized Difference Vegetation Index (NDVI), red and near-infrared (NIR) data for native, mixed and Eragrostis lehmanniana (ERLE) sites through years 2000 to 2005, represented by using the mean coefficient of variation (all values are percentages). The difference among each type of site in six years (overall) is compared using the autoregressive model of lag 1 and set the one-tailed significance level to 0.05 . Note that values with different superscripts $(\mathrm{a}, \mathrm{b}$ or $\mathrm{c})$ have significant difference.

\begin{tabular}{lcrrrrrrc}
\hline Index & Site & 2000 & 2001 & 2002 & 2003 & 2004 & 2005 & Overall \\
\hline NDVI & Native & 15.0 & 15.2 & 18.7 & 20.6 & 18.6 & 16.3 & $17.5^{\mathbf{a}}$ \\
& Mixed & 11.6 & 14.1 & 15.4 & 11.5 & 8.9 & 11.1 & $12.1^{\mathbf{b}}$ \\
& ERLE & 12.1 & 10.6 & 15.6 & 15.2 & 9.6 & 8.2 & $11.9^{\mathbf{b}}$ \\
\multirow{3}{*}{ Red } & Native & 12.1 & 18.1 & 15.5 & 16.5 & 16.2 & 14.9 & $15.6^{\mathbf{a}}$ \\
& Mixed & 9.6 & 15.3 & 10.4 & 10.7 & 12.9 & 14.2 & $12.2^{\mathbf{b}}$ \\
& ERLE & 12.3 & 11.7 & 8.2 & 10.6 & 8.7 & 11.6 & $10.5^{\mathbf{c}}$ \\
\multirow{2}{*}{ NIR } & Native & 11.6 & 9.3 & 9.5 & 10.4 & 8.6 & 7.5 & $9.4^{\mathbf{b}}$ \\
& Mixed & 7.1 & 9.1 & 7.8 & 7.9 & 10.9 & 13.6 & $9.5^{\mathbf{b}}$ \\
& ERLE & 10.8 & 8.9 & 11.1 & 12.2 & 8.2 & 11.6 & $10.5^{\mathbf{a}}$ \\
\hline
\end{tabular}


season, contamination from bright-coloured inflorescence and standing litter would suppress the green signals of E. lehmanniana (van Leeuwen and Huete 1996, Gao et al. 2000). Hence, our results do not support the first prediction: spectral vegetation signals are greater in E. lehmanniana-infested sites during the summer growing season.

The NDVI is a metric highly correlated with photosynthetic activity and associated greenness (Tucker and Sellers 1986). Our data also showed a similar tendency revealing that the NDVI was a salient variable $(p \leqslant 0.002)$ to estimate herbaceous biomass, regardless of the invasion of $E$. lehmanniana (figure 4). However, the model predictions were not compelling (low $R^{2}$ ). In addition to the aforementioned $E$. lehmanniana morphology factor limiting the prediction of herbaceous biomass using the NDVI $\left(R^{2}=0.35\right.$ for native sites and $R^{2} \leqslant 0.23$ for $E$. lehmanniana-infested sites), there are two possible causes. Firstly, in arid and semiarid environments, bright soil background occupies a substantial amount of land surface. It could also contaminate the green signal and was very difficult to unravel in visible and near-infrared spectral regions (Asner and Heidebrecht 2002). Secondly, we collected standing biomass of herbaceous plants including both photosynthetic green tissues and non-photosynthetic litter. The latter component may not be discerned by the NDVI.

\subsection{Effects of biodiversity on NDVI temporal variation and spatial heterogeneity}

Plant biodiversity may be one of the key factors that separated NDVI time-series data in spring and/or early summer between these sites (figure 5(a)). During this time period, the green vegetation signals were mainly from annual grasses and herbaceous dicots, and there was a lack of these species in E. lehmanniana-infested sites (mixed/ERLE) (figure 3; Geiger 2006). Therefore, native sites consistently produced higher NDVI values during spring and/or early summer (table 3 ). This finding supports our second prediction: during non-growing time periods, vegetation signals would be stronger in native grass dominant sites because they support a greater number of annual grasses and herbaceous dicots than $E$. lehmanniana-infested sites.

Our NDVI analysis indicated that between years, temporal variation for plant communities was much greater than the within-year variation among them (table 4), and the response of the NDVI to precipitation among sites was quite similar across multiple years (figure 5(a)). However, the annual temporal variation of the NDVI values in native sites was consistently lower than in $E$. lehmanniana-infested sites (mixed/ERLE) based on a direct comparison of the $\mathrm{CV}$, regardless of wet or dry climate. The major factor contributing to low temporal variation of NDVI values in native sites may also be biodiversity. According to field observations, several perennial/annual grasses, herbaceous dicots, perennial vines and small-sized shrubs were dominant in the native sites. Different species and life forms can coexist with different rooting depths and growing seasons (Fargione and Tilman 2005). Therefore, there should be some level of greenness in native sites throughout the year. Hence, temporal variation of NDVI values in native sites was lower than Eragrostis lehmanniana-infested sites. E. lehmanniana formed spatially homogeneous landscapes (figure 1) by generating a dense uni-tonal layer (green in growing seasons, yellowish otherwise) with lower within-plant community group CV values, regardless of wet or dry conditions (table 5). Therefore, E. lehmanniana invaded sites (mixed/ERLE) 
generated lower temporal-spatial variation in NDVI values than native sites. Our findings therefore support the first part of the third prediction: remote sensing vegetation data in native sites are more temporally stable but spatially variable than E. lehmanniana-invaded sites, and plant species diversity could be the determinant that controls this variation.

\subsection{MODIS red reflectance time-series data}

The temporal profile of the MODIS red reflectance displays an inverse pattern compared to the NDVI profile (figure 5(c)). The larger values occurred during the driest and hottest time (May/June) due to the high brightness from litter and soils and low chlorophyll concentration in plant tissue. In contrast to the dry premonsoon period, sites yielded the lowest values of red reflectance during the summer monsoons because of the strong absorption by chlorophyll from actively growing vegetation. There was almost no distinct separation of the MODIS red reflectance time-series data between different plant communities (table 3), and temporal variation among native, mixed and ERLE sites were quite similar (table 4). The response of MODIS red reflectance trajectories did not fully reflect the phenology of plant communities. This was likely because: (1) the dynamic range (the range between minimum and maximum reflectance) of the red reflectance values in vegetated areas was low and (2) factors unrelated to vegetation, such as brightness of soil background, substantially altered the reflectance values. Hence, our results do not support the part of the third prediction that stated: remote sensing red reflectance in native grass dominant sites is temporally more stable than $E$. lehmanniana invaded sites.

However, the difference in combined temporal-spatial variation in the red reflectance values between native grass dominated and E. lehmanniana-infested sites was apparent (figure 5(d) and table 5). The temporal-spatial variation of native sites was higher than mixed and ERLE, and the temporal-spatial variation of the MODIS red reflectance was the only index capable of discerning the plant community transition (native $\rightarrow$ mixed $\rightarrow$ ERLE). Our results based on the AR(1) time-series test support an important aspect of the third prediction: remote sensing brightness data in native grass-dominated sites are more spatially variable than $E$. lehmanniana-infested sites (mixed/ERLE).

\subsection{Issues with using MODIS NIR time-series data}

Temporal trends in the MODIS NIR reflectance data were similar to the NDVI time-series data, but more variable (figure 5(e)). Dynamics of NIR data may not entirely correspond to green vegetation because: (1) NIR reflectance data for bright litter and soil is as high as that of green grass and (2) decomposition of litter could significantly lower the NIR reflectance. In addition, contributions to variation in the data might include sensor view angle variability, sub-pixel cloud cover, sensor calibration, remnant geometric errors, atmosphere and/or surface anisotropy (Holben 1986, Gutman 1991, Viovy et al. 1992, Jönsson and Eklundh 2002, van Leeuwen et al. 2006). The main summer growing season can be distinguished, but the secondary spring growing seasons (2001 and 2004) were not as apparent as those shown in the NDVI. The season(s), when discrimination of native, mixed and ERLE sites was possible in the NIR spectral region, were unpredictable (table 3 ) and this might result from variation in data uncertainty. 
Temporal variation in the NIR among native, mixed and ERLE sites were quite similar (table 4). The NIR data variation might obscure the subtle signal difference among native and E. lehmanniana-infested sites. The difference of NIR temporal-spatial variations among sites was less apparent than that of the NDVI and red reflectance (table 5) data. NIR reflectance data alone was not an effective indicator to differentiate phenological details among plant communities due to substantial data variation. Therefore, we are not able to test predictions using NIR data.

\subsection{Implications for non-native plant management}

This study demonstrates that phenological and ecophysiological characteristics of native, transitional (mixed) and E. lehmanniana-dominant (ERLE) plant communities can be delineated using MODIS NDVI and red reflectance time-series data. The following is a summary of our findings:

(1) The native plant community sites produced more greenness than $E$. lehmanniana-infested areas year long in most cases and especially in the spring/early summer, mainly due to the contribution from annual grasses and herbaceous dicots. In addition, E. lehmanniana can generate a significant amount of bright-coloured biomass and standing litter that may inhibit green signals and result in low predictability of the NDVI to herbaceous biomass in semi-desert grasslands.

(2) Temporal variation of the NDVI in the native plant community was consistently lower than $E$. lehmanniana-infested communities. The native plant community consisted of several perennial and annual grasses, herbaceous dicots and small-sized shrubs with different growing periods. Hence, there is a greater consistency in the amount of greenness in the native plant community through seasons resulting in low NDVI temporal variation.

(3) Eragrostis lehmanniana vegetation generated distinguishably lower temporalspatial variation of the NDVI and red reflectance. Eragrostis lehmanniana formed a homogeneous landscape, which was a dense uni-tonal layer of green grass or yellowish litter stratum. In contrast, native plant communities contained higher biodiversity, forming a more complex landscape with time.

By coupling these temporally and spatially unique signatures from low cost vegetation and brightness time-series satellite data, field observations and statistical models (e.g. a regression tree model; Meentemeyer et al. 2001), we can now begin to regularly monitor the spread of E. lehmanniana over this vast arid region, after taking into account the uncertainties induced by the spatial and temporal variability of precipitation. This information is pivotal for the control and management of nonnative plants over large spatial extents.

\section{Acknowledgements}

The authors would like to thank M. McClaran for providing insightful suggestions to improve the quality of this work. We wish to acknowledge funding from the US Army Medical Research and Materiel Command (DAMD17-99-2-9049), NSF Doctoral Dissertation Research Improvement Grant Program (BCS-0525939), and T\&E Inc. Grants for Conservation Biology Research. 


\section{References}

Al-BAKRI, J.T. and TAYlor, J.C., 2003, Application of NOAA AVHRR for monitoring vegetation conditions and biomass in Jordan. Journal of Arid Environments, 54, pp. 579-593.

Anderson, G.L., Carruthers, R.I., Ge, S. and Gong, P., 2005, Cover: monitoring of invasive Tamarix distribution and effects of biological control with airborne hyperspectral remote sensing. International Journal of Remote Sensing, 26, pp. 2487-2489.

Anderson, G.L., Everitt, J.H., Richardson, A.J. and Escobar, D.E., 1993a, Using satellite data to map false broomweed (Ericameria austrotexana) infestations on south Texas rangelands. Weed Technology, 7, pp. 865-871.

Anderson, G.L., Hanson, J.D. and HaAs, R.H., 1993b, Evaluating Landsat Thematic Mapper derived vegetation indices for estimating above-ground biomass on semiarid rangelands. Remote Sensing of Environment, 45, pp. 165-175.

AsNer, G.P., 1998, Biophysical and biochemical sources of variability in canopy reflectance. Remote Sensing of Environment, 64, pp. 234-253.

Asner, G.P. and Heidebrecht, K.B., 2002, Spectral unmixing of vegetation, soil and dry carbon cover in arid regions: comparing multispectral and hyperspectral observations. International Journal of Remote Sensing, 23, pp. 3939-3958.

Asner, G.P. and Vitousek, P.M., 2005, From the cover: remote analysis of biological invasion and biogeochemical change. Proceedings of the National Academy of Sciences USA, 102, pp. 4383-4386.

Begon, M., Harper, J.L. and Townsend, C.R., 1996, Ecology: Individuals, Populations and Communities, 3rd edn (London, UK: Blackwell Science).

BELSKY, J.A., 1990, Tree/grass ratios in East African savannas: a comparison of existing models. Journal of Biogeography, 17, pp. 483-489.

Biggs, T.H., Quade, J. and WeBb, R.H., 2002, $C$ values of soil organic matter in semiarid grassland with mesquite (Prosopis) encroachment in southeastern Arizona. Geoderma, 110, pp. 109-130.

Bock, C.E., Bock, J.H., Jepson, K.L. and Ortega, J.C., 1986, Ecological effects of planting African lovegrasses in Arizona. National Geographic Research, 2, pp. 456-463.

BRAdLEY, B.A. and MustARD, J.F., 2005, Identifying land cover variability distinct from land cover change: cheatgrass in the Great Basin. Remote Sensing of Environment, 94, pp. 204-213.

CAble, D.R., 1971, Lehmann lovegrass on the Santa Rita Experimental Range, 1937-1968. Journal of Range Management, 24, pp. 17-21.

Cox, J.R. and RuYle, G.B., 1986, Influence of climatic and edaphic factors on the distribution of Eragrostis lehmanniana Nees in Arizona, USA. Journal of Grassland Society of South Africa, 3, pp. 25-29.

Cox, J.R., Martin-R, M.H., Ibarra-F, F.A., Fourie, J.H., Rethman, N.F.G. and Wilcox, D.G., 1988, The influence of climate and soils on the distribution of four African grasses. Journal of Range Management, 41, pp. 127-139.

D’Antonio, C.M. and Vitousek, P.M., 1992, Biological invasions by exotic grasses, the grass/fire cycle, and global change. Annual Review of Ecology and Systematics, 23, pp. 63-87.

DraKe, S.E., 2000, Climate-correlative modeling of phytogeography at the watershed scale. PhD thesis, University of Arizona, Tucson, AZ, USA.

Dregne, H.E. and TuCKer, C.J., 1988, Green biomass and rainfall in semi-arid sub-Saharan Africa. Journal of Arid Environments, 15, pp. 245-252.

Everitt, J.H., Anderson, G.L., Escobar, D.E., Davis, M.R., Spencer, N.R. and ANDRASCIK, R.J., 1995, Use of remote sensing for detecting and mapping leafy spurge (Euphorbia esula). Weed Technology, 9, pp. 599-609. 
Everitt, J.H., Escobar, D.E., Alaniz, M.A., Davis, M.R. and Richerson, J.V., 1996, Using spatial information technologies to map Chinese tamarisk (Tamarix chinensis) infestations. Weed Science, 44, pp. 194-201.

Everitt, J.H., Escobar, D.E. and Davis, M.R., 2001, Reflectance and image characteristics of selected noxious rangeland species. Journal of Range Management, 54, pp. A106-A120.

FARgione, J. and Tilman, D., 2005, Niche differences in phenology and rooting depth promote coexistence with a dominant C4 bunchgrass. Oecologia, 143, pp. 598-606.

Fuller, D.O., 2005, Remote detection of invasive Melaleuca trees (Melaleuca quinquenervia) in South Florida with multispectral IKONOS imagery. International Journal of Remote Sensing, 26, pp. 1057-1063.

Gao, X., Huete, A., Ni, W. and Miura, T., 2000, Optical-biophysical relationships of vegetation spectra without background contamination. Remote Sensing of Environment, 74, pp. 609-620.

Geiger, E.L., 2006, The role of fire season and a nonnative grass as disturbances in semidesert grasslands. PhD thesis, University of Arizona, Tucson, AZ, USA.

Glenn, N.F., Mundt, J.T., Weber, K.T., Prather, T.S., Lass, L.W. and Pettingill, J., 2005, Hyperspectral data processing for repeat detection of small infestations of leafy spurge. Remote Sensing of Environment, 95, pp. 399-412.

Gutman, G.G., 1991, Vegetation indices from AVHRR: an update and future prospects. Remote Sensing of Environment, 35, pp. 121-136.

Holben, B.N., 1986, Characteristics of maximum-value composite images from temporal AVHRR data. International Journal of Remote Sensing, 7, pp. 1417-1434.

Huete, A., Didan, K., Miura, T., Rodriguez, E.P., Gao, X. and Ferreira, L.G., 2002, Overview of the radiometric and biophysical performance of the MODIS vegetation indices. Remote Sensing of Environment, 83, pp. 195-213.

Hurcom, S.J. and HARrison, A.R., 1998, The NDVI and spectral decomposition for semiarid vegetation abundance estimation. International Journal of Remote Sensing, 19, pp. 3109-3125.

JönSSON, P. and EKLUNDH, L., 2002, Seasonality extraction by function fitting to time series of satellite sensor data. IEEE Transactions on Geoscience and Remote Sensing, 40, pp. $1824-1832$.

Justice, C., Hall, D., Salomonson, V., Privette, J., Riggs, G., Strahler, A., Lucht, W., Myneni, R., Knjazihhin, Y., Running, S., Nemani, R., Vermote, E., Townshend, J., Defries, R., Roy, D., WAN, Z., Huete, A., van Leeuwen, W.J.D., Wolfe, R., Giglio, L., Muller, J.-P., Lewis, P. and BARnSLEY, M., 1998, The Moderate Resolution Imaging Spectroradiometer (MODIS): land remote sensing for global change research. IEEE Transactions on Geoscience and Remote Sensing, 36, pp. 1228-1249.

Justice, C.O., Townshend, J.R.G., Holben, B.N. and Tucker, C.J., 1985, Analysis of the phenology of global vegetation using meteorological satellite data. International Journal of Remote Sensing, 6, pp. 1271-1318.

Lawrence, R.L., Wood, S.D. and Shelley, R.L., 2006, Mapping invasive plants using hyperspectral imagery and Breiman Cutler classifications (random forest). Remote Sensing of Environment, 100, pp. 356-362.

McPherson, G.R., 1995, The role of fire in the desert grasslands. In The Desert Grassland, M. McClaran and T.R. van Devender (Eds), pp. 130-151 (Tucson, AZ, USA: University of Arizona Press).

McPherson, G.R., 1997, Ecology and Management of North American Savannas (Tucson, AZ, USA: University of Arizona Press).

McPherson, G.R. and Weltzin, J.F., 2000, The Role and Importance of Disturbance and Climate Change in U.S./Mexico Borderlands: A State-of-the-knowledge 
Review (Fort Collins, CO, USA: USDA Forest Service Rocky Mountain Research Station).

Meentemeyer, R.K., Moody, A. and Franklin, J., 2001, Landscape-scale patterns of shrub-species abundance in California chaparral: the role of topographically mediated resource gradients. Plant Ecology, 156, pp. 19-41.

Miao, X., Gong, P., Swope, S., Pu, R., Carruthers, R., Anderson, G.L., Heaton, J.S. and TRACY, C.R., 2006, Estimation of yellow starthistle abundance through CASI-2 hyperspectral imagery using linear spectral mixture models. Remote Sensing of Environment, 101, pp. 329-341.

Okin, G.S., Roberts, D.A., Murray, B. and Okin, W.J., 2001, Practical limits on hyperspectral vegetation discrimination in arid and semiarid environments. Remote Sensing of Environment, 77, pp. 212-225.

Ortega, Y.K. and Pearson, D.E., 2005, Weak versus strong invaders of natural plant communities: Assessing invasibility and impact. Ecological Applications, 15, pp. 651-661.

Prince, S.D. and Tucker, C.J., 1986, Satellite remote sensing of rangelands in Botswana II. NOAA AVHRR and herbaceous vegetation. International Journal of Remote Sensing, 7, pp. $1555-1570$.

Ramsey, F.L. and Schafer, D.W., 1997, The Statistical Sleuth: A Course in Methods of Data Analysis (Pacific Grove, CA, USA: Duxbury Press).

Reed, B.C., Brown, J.F., Vanderzee, D., Loveland, T.R., Merchant, J.W. and OHLEN, D.O., 1994, Measuring phenological variability from satellite imagery. Journal of Vegetation Science, 5, pp. 703-714.

Rouse Jr., J., Haas, R., Deering, D., Schell, J. and Harlan, C., 1974, Monitoring the Vernal Advancement and Retrogradation (Green Wave Effect) of Natural Vegetation (Greenbelt, MD, USA: NASA).

Scholes, R.J. and ARCHER, S.R., 1997, Tree-grass interactions in savannas. Annual Review of Ecology and Systematics, 28, pp. 517-544.

Schussman, H., Geiger, E., Mau-Crimmins, T. and Ward, J., 2006, Spread and current potential distribution of an alien grass, Eragrostis lehmanniana Nees, in the southwestern USA: comparing historical data and ecological niche models. Diversity and Distributions, 12, pp. 582-592.

Tucker, C.J. and Sellers, P.J., 1986, Satellite remote sensing for primary production. International Journal of Remote Sensing, 7, pp. 1395-1416.

Tucker, C.J., Vanpraet, C.L., Sharman, M.J. and Vanittersum, G., 1985, Satellite remote sensing of total herbaceous biomass production in the Senegalese Sahel: 1980 1984. Remote Sensing of Environment, 17, pp. 233-249.

Underwood, E., Ustin, S. and Dipietro, D., 2003, Mapping nonnative plants using hyperspectral imagery. Remote Sensing of Environment, 86, pp. 150-161.

van Leeuwen, W.J.D. and Huete, A.R., 1996, Effects of standing litter on the biophysical interpretation of plant canopies with spectral indices. Remote Sensing of Environment, 55, pp. 123-138.

van Leeuwen, W.J.D., OrR, B., Marsh, S.E. and Herrmann, S., 2006, Multi-sensor NDVI data continuity: uncertainties and implications for vegetation monitoring applications. Remote Sensing of Environment, 100, pp. 67-81.

Viovy, N., Arino, O. and Belward, A.S., 1992, The best index slope extraction (BISE): a method for reducing noise in NDVI time series. International Journal of Remote Sensing, 13, pp. 1585-1590.

Williams, D.G. and BARUCH, Z., 2000, African grass invasion in the Americas: ecosystem consequences and the role of ecophysiology. Biological Invasions, 2, pp. $123-140$.

Wolfe, R.E., Nishihama, M., Fleig, A.J., Kuyper, J.A., Roy, D.P., Storey, J.C. and PATT, F.S., 2002, Achieving sub-pixel geolocation accuracy in support of MODIS land science. Remote Sensing of Environment, 83, pp. 31-49. 
Wylie, B.K., Harrington JR., J.A., Prince, S.D. and Denda, I., 1991, Satellite and groundbased pasture production assessment in Niger: 1986-1988. International Journal of Remote Sensing, 12, pp. 1281-1300. 